\title{
Reduced PAK1 activity sensitizes FA/BRCA-proficient breast cancer cells to PARP inhibition
}

\author{
Olga Villamar Cruz ${ }^{1, *}$, Tatiana Y. Prudnikova ${ }^{2,}{ }^{*}$, Daniela Araiza-Olivera ${ }^{2}$, Carlos \\ Perez-Plasencia ${ }^{1}$, Neil Johnson ${ }^{3}$, Andrea J. Bernhardy ${ }^{3}$, Michael Slifker ${ }^{4}$, Catherine \\ Renner $^{5}$, Jonathan Chernoff ${ }^{2}$ and Luis E. Arias-Romero ${ }^{1}$ \\ ${ }^{1}$ UBIMED, Facultad de Estudios Superiores-Iztacala, UNAM, Tlalnepantla, Estado de México, Mexico \\ ${ }^{2}$ Cancer Biology Program, Fox Chase Cancer Center, Philadelphia, PA, USA \\ ${ }^{3}$ Experimental Therapeutics Program, Fox Chase Cancer Center, Philadelphia, PA, USA \\ ${ }^{4}$ Department of Biostatistics and Bioinformatics, Fox Chase Cancer Center, Philadelphia, PA, USA \\ ${ }^{5}$ Department of Pathology, Fox Chase Cancer Center, Philadelphia, PA, USA \\ * These authors have contributed equally to this work \\ Correspondence to: Luis E. Arias-Romero, email: larias@campus.iztacala.unam.mx
} Jonathan Chernoff, email: Jonathan.Chernoff@fccc.edu

Keywords: transformation, PAK1, DNA repair, Fanconi Anemia, small molecule inhibitor

Received: June 21,2016 Accepted: October 07, 2016 Published: October 11, 2016

\section{ABSTRACT}

Cells that are deficient in homologous recombination, such as those that have mutations in any of the Fanconi Anemia (FA)/BRCA genes, are hypersensitive to inhibition of poly(ADP-ribose) polymerase (PARP). However, FA/BRCA-deficient tumors represent a small fraction of breast cancers, which might restrict the therapeutic utility of PARP inhibitor monotherapy. The gene encoding the serinethreonine protein kinase p21-activated kinase 1 (PAK1) is amplified and/or overexpressed in several human cancer types including $25-30 \%$ of breast tumors. This enzyme controls many cellular processes by phosphorylating both cytoplasmic and nuclear substrates. Here, we show that depletion or pharmacological inhibition of PAK1 down-regulated the expression of genes involved in the FA/BRCA pathway and compromised the ability of cells to repair DNA by Homologous Recombination (HR), promoting apoptosis and reducing colony formation. Combined inhibition of PAK1 and PARP in PAK1 overexpressing breast cancer cells had a synergistic effect, enhancing apoptosis, suppressing colony formation, and delaying tumor growth in a xenograft setting. Because reduced PAK1 activity impaired FA/BRCA function, inhibition of this kinase in PAK1 amplified and/or overexpressing breast cancer cells represents a plausible strategy for expanding the utility of PARP inhibitors to FA/BRCA-proficient cancers.

\section{INTRODUCTION}

p21-activated kinases (PAKs) are effectors for the small GTPases Cdc42 and Rac that control several cellular processes, including cell morphology, motility, survival, gene transcription, apoptosis and hormone signaling [1-3]. These enzymes are widely expressed in numerous tissues and are activated by extracellular signals through GTPasedependent and -independent mechanisms [4]. In addition, it has been shown that a gene encoding one member of the PAK family, PAK1, located on human chromosome 11q13, is amplified and/or overexpressed in several human cancer types, including $25-30 \%$ of breast tumor samples and cancer cell lines [3]. In addition to its well-characterized kinase activity, it is documented that PAK1 translocates into the nucleus and associates with chromatin, suggesting that it might be involved in gene transcription $[5,6]$. More recently, PAK1 signaling has emerged as a component of the DNA damage response as PAK1 activity influences the cellular sensitivity to ionizing radiation $[7,8]$.

When the DNA is damaged, it is repaired by two different mechanisms. PARP is involved in the repair of DNA single-strand breaks (SSBs), and when it is inhibited, DNA SSBs degenerate to more lethal DNA double- 
strand breaks (DSBs) that require repair by homologous recombination (HR), which requires the activation of the Fanconi Anemia (FA)/BRCA pathway, a DNA-damage response signaling pathway which is essential for the repair of DNA interstrand cross-links induced by DNAdamaging agents [9-11]. Therefore, FA/BRCA-deficient cells and other cells that are defective in homologous recombination are highly susceptible to poly(ADP-ribose) polymerase (PARP) inhibition $[12,13]$.

Here, we show that some genes involved in the FA/ BRCA pathway are down-regulated in PAK1 deficient cells. The expression of two FA genes, FANCD2 and FANCI, was confirmed by qPCR and western blot in PAK1 depleted human breast cancer cells with or without $P A K 1$ amplification and/or overexpression. Interestingly, the depletion or chemical inhibition of PAK in PAK1 amplified or overexpressing breast cancer cells treated with DNA damaging agents, compromised the ability of these cells to form Rad51 foci, induced cell cycle arrest, promoted apoptosis and resulted in reduced colony formation. In contrast, the inhibition or depletion of PAK1 had little effect on these cellular processes in PAK1-non-amplified breast cancer cells. Finally, we showed that combined inhibition of PAK and PARP had a synergistic effect in $P A K 1$ amplified or overexpressing breast cancer cells, were the dual inhibition of these molecules totally abrogated colony formation, enhanced apoptosis and impaired tumor growth in a xenograft setting. Interestingly, the ectopic overexpression of PAK1 in PAK1-non-amplified breast cancer cells recapitulated the sensitivity to combined inhibition of PAK and PARP observed in PAK1-amplified breast cancer cells, suggesting that PAK1 is involved in DNA repair by HR through a FA/ BRCA dependent pathway. These findings indicate that depletion or inhibition of PAK1 creates a state of "FA/ BRCAness" in transformed cells and represents a rational approach for expanding the utility of PARP inhibitors to FA/BRCA-proficient cancers.

\section{RESULTS}

\section{Fanconi anemia genes are down-regulated in PAK1 deficient Cells}

To identify differentially regulated genes between wild-type and PAK1 deficient mouse and human breast cancer cells, we extracted total RNA from the genetically engineered human cell line MCF10A.B2 expressing an inducible shRNA against PAK1, and from PAK1-/- breast cancer cell lines derived from murine tumors [14], and performed a comparative gene profiling study by using human or mouse whole genome arrays. A considerable number of differentially expressed genes between wildtype and PAK1 deficient human breast cancer cells were also found differentially expressed in mouse breast cancer cells (Figure 1A). Interestingly, several genes involved in the FA/BRCA pathway, a DNA-damage response signaling pathway which is essential for the repair of DNA interstrand cross-links induced by DNA-damaging agents like cisplatin and doxorubicin [15, 16], were down-regulated in PAK1 deficient cells (Figure 1B). To test if the down-regulation of the aforementioned genes correlated with $P A K 1$ expression levels, the total amount of PAK1 and its phosphorylation levels were confirmed by western blot in the PAK1 non-amplified breast cancer cell line HCC1419, the PAK1 overexpressing cell lines BT-474 and MDA-MB-361 and the PAK1 amplified breast cancer cell line SK-BR-3 (Figure S1A). Next, the expression level of two FA/BRCA genes, FANCD2 and FANCI, was confirmed by qPCR and western blot in PAK1 depleted human breast cancer cells (Figure 1C and 1D). Interestingly, the absence of $P A K 1$ drastically affected the expression of the FA/BRCA genes in the breast cancer cell lines with amplification and/or overexpression of $P A K 1$ and had little effect in breast cancer cells with low expression levels of this protein kinase. These findings are consistent with a recent study were a TCGA analysis showed that $P A K 1$ overexpression was correlated with the expression of $B R C A 1$ and $B R C A 2$ in inflammatory breast cancer [17]. Finally, the results of a TCGA analysis we performed showed that $P A K 1$ overexpression in human breast cancer samples correlates with the expression of most FA/BRCA genes, particularly with FANCI (Figure $\mathrm{S} 1 \mathrm{~B})$.

\section{PAK1 depletion or inhibition sensitizes $11 q 13$ amplified breast cancer cells to DNA damaging agents}

Since FA/BRCA deficient cells are defective in the formation of Rad51 foci, which is a crucial component of the HR repair machinery $[11,18]$, we examined the effect of PAK inhibition in the ability of FA/BRCA proficient cells to form these foci. To this end, the breast cancer cell lines with or without $P A K 1$ amplification and/or overexpression, were treated with vehicle or PF-3758309, a small molecule inhibitor of Group A and Group B PAKs [19], or transfected with PAK1 targeting siRNAs, and DNA damage was induced with cisplatin. Interestingly, we found that PAK inhibition or depletion in PAK1 amplified or overexpressing breast cancer cells significantly reduced the formation of Rad51 foci, but had no effect in PAK1 non-amplified breast cancer cells which were able to form $\operatorname{Rad} 51$ foci in response to DNA damaging agents (Figure 2A and 2B). These data strongly suggest that PAK inhibition affects DNA repair by HR only in FA/ BRCA proficient breast cancer cells with amplification or overexpression of $P A K 1$. 

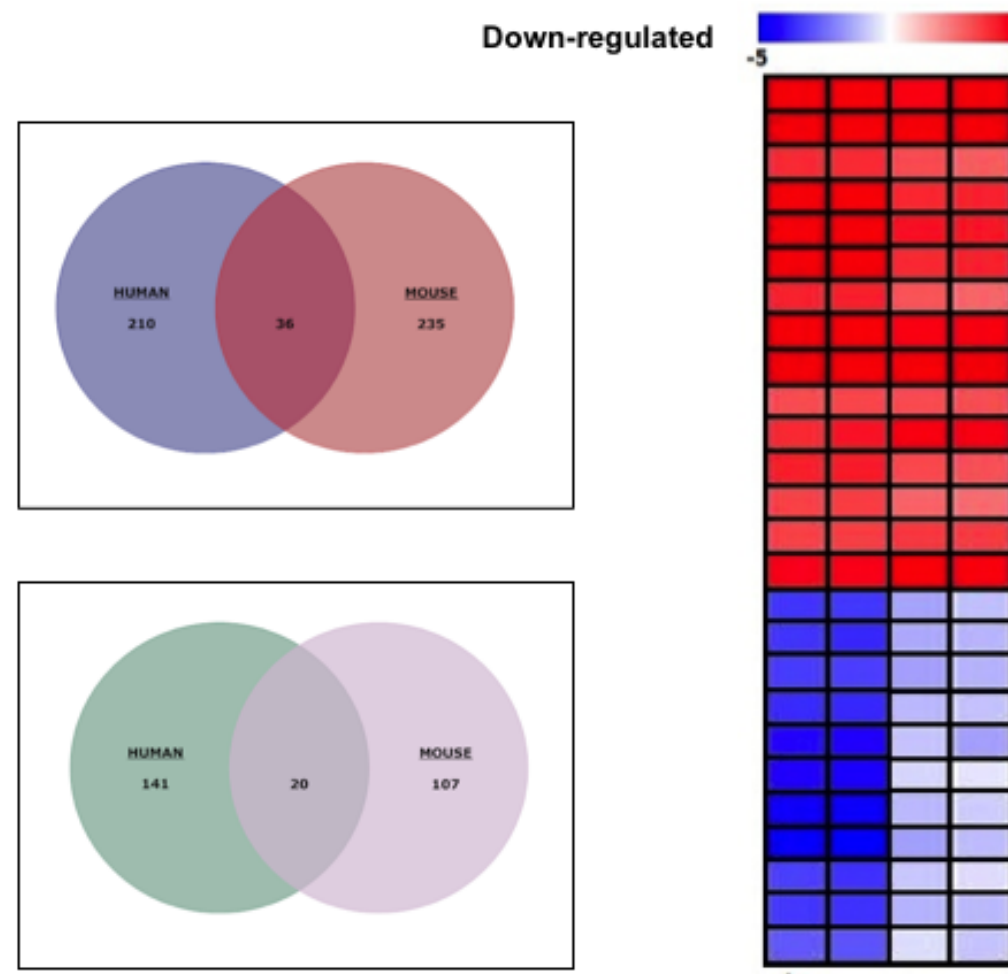

Up-regulated

CXCL10

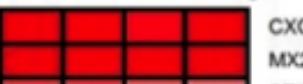

MO2 2

STAT2

IFIT2

IFIH1

TNFSF10

OAS3

CCLS

IRF7

IRF9

GBP2

PARP9

PARP10

PARP12

PARP14

FANCD2

$\mathrm{FANCl}$

MND1

CDK1

CCNB1

CCNA2

MKI67

CDC25C

RACGAP1

KIF23

IQGAP3

Immune

Response

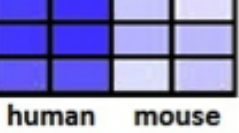

(1)

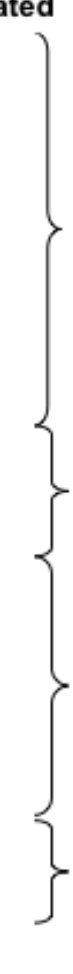

PARP

Family

Genes

Cell Cycle

and DNA

repair

Cytoskeletal

Functions
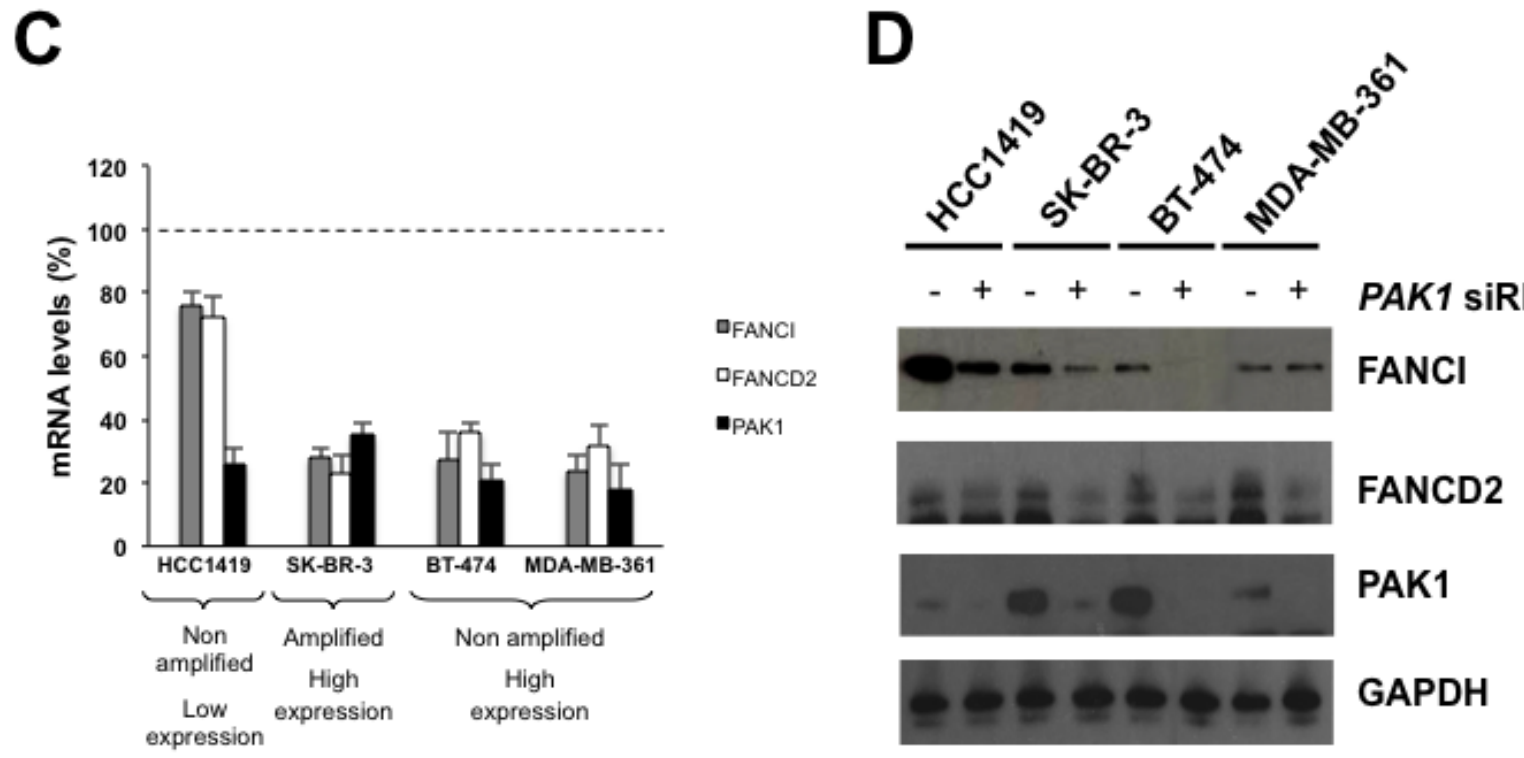

Figure 1: PAK inhibition down-regulates FA genes. A. Venn diagrams showing differentially regulated genes between wild-type and PAK1 deficient mouse and human breast cancer cells. The upper panel shows the up-regulated genes and the lower panel the downregulated genes. B. Heat map representation of microarray data. Genes were classified according to their cellular function. The color scale represents the expression level of a gene above (red) or below (blue) the mean expression levels across the samples. C. qPCR validation of microarray data. PAK1-overexpressing and/or amplified, and non-amplified breast cancer cells were transfected with non-targeting or $P A K 1$ targeting siRNAs. All data were normalized to control GAPDH. Fold changes were calculated using the $\Delta \mathrm{Ct}$ method (2- $\Delta \Delta \mathrm{Ct})$. Error bars depict the standard error of the mean $\Delta \mathrm{Ct}$ values. Significant differences $(P<0.05)$ are denoted with a star. D. Western blot analysis showing the down-regulation of FA genes in PAK1 depleted cells. PAK1 amplified and non-amplified breast cancer cells were transfected with non-targeting or PAK1 targeting siRNAs, total protein was extracted and western blots were performed using the indicated antibodies. 


\section{PAK1 depletion or inhibition reduces cell survival}

Next, we examined if PAK inhibition impacts cell survival in long-term colony formation assays. HCC1419, BT-474, MDA-MB-361 and SK-BR-3 breast cancer cells were treated with vehicle or PF-3758309, or transfected with $P A K 1$ targeting siRNAs and exposed to cisplatin. As expected, PAK inhibition had little effect on the survival of HCC1419 cells, even in the presence of cisplatin. However, PAK depletion or inhibition caused more than $50 \%$ reduction in the survival of BT- 474 , MDA-MB-361 and SK-BR-3 cells treated with cisplatin (Figure $3 \mathrm{~A}$ and $3 \mathrm{~B}$ ). To determine whether PAK inhibition could promote cell death in these cells, we calculated the percentage of apoptotic cells in HCC1419, BT-474, MDA-MB-361 and SK-BR-3 breast cancer cells treated with vehicle, PF-3758309 or transfected with PAK1 targeting siRNAs and incubated with cisplatin. Consistent with our previous results, we found that breast cancer cells with amplification or overexpression of $P A K 1$ are highly sensitive to cisplatin-induced apoptosis after $P A K 1$ inhibition or depletion, whereas PAK blockade has a very modest effect in HCC1419 breast cancer cells (Figure 3C).

\section{Reduced PAK1 activity sensitizes breast cancer cells to PARP inhibition}

Since FA/BRCA deficient cells and other cells that are deficient in HR are highly susceptible to PARP small molecule inhibitors [11, 20, 21], we hypothesized that PAK inhibition could sensitize PAKl amplified or overexpressing beast cancer cells to PARP pharmacological inhibition. To this end we tested the effect of small molecule inhibitors of PAK and PARP, alone and together, on Rad51 foci formation in breast cancer cells with amplification or overexpression of PAK1. These compounds included PF-3758309 and Rucaparib, which is a potent inhibitor of PARP-1 and PARP-2 [22].

SK-BR-3, BT-474, MDA-MB-361 (PAK1 amplified and/or overexpressing cells) and HCC1419 cells were treated with these inhibitors and cisplatin, and the effect on Rad 51 foci formation was assessed following 3 days of treatment. As expected, there are no differences on the $\gamma-\mathrm{H} 2 \mathrm{AX}$ foci number among all the cell lines tested, independently of PAK1 expression levels. However, PAK inhibition significantly affected the formation of Rad51 foci only in PAK1-amplified and/or overexpressing cells, and this effect is much more drastic in cells treated with both, PAK and PARP inhibitors and exposed to cisplatin (Figure 4). To test the effect of dual inhibition of PAK and PARP in the survival of breast cancer cells, we performed a synergy test (Figure 5A and Table 1). The PARP inhibitor alone had a nearly identical effect in the survival of all breast cancer cell lines, and as expected, PAK1 overexpressing and $P A K 1$-amplified breast cancer cells were much more sensitive to PAK inhibition than HCC1419 cells. The IC50 values for Rucaparib in BT474, MDA-MB-361, SK-BR3 and HCC1419 cells were $101.46,98.8,98.1$ and $102.3 \mathrm{nmol} / \mathrm{L}$ respectively; and the IC50 values for PF-3758309 were 74.3, 66.8, 65.6 and $97.0 \mathrm{nmol} / \mathrm{L}$ respectively. However, when the compounds were coadministered, a marked synergistic effect was noted only in PAK1 overexpressing and PAK1-amplified breast cancer cells [combination index $(\mathrm{CI})<0.5$; Figure 5A and Table 1]. Coadministration of PF-3758309 and Rucaparib yielded CI values of $19.8,21.5$ and $19.3 \mathrm{nmol} / \mathrm{L}$ in BT-474, MDA-MB-361 and SK-BR-3 cells, indicating a high degree of synergy, whereas this effect was not seen in HCC1419 cells (Figure 5A). Next, we examined if combined PAK and PARP inhibition affects cell survival in colony formation assays. Treatment of HCC1419 cells with each of these drugs reduced approximately $20 \%$ the number of colonies, and the coadministration of both compounds caused a $35 \%$ reduction in the number of colonies. Treatment of PAK1 overexpressing and PAK1amplified breast cancer cells with each of these drugs had a similar effect, and interestingly, coadministration of both inhibitors caused a very significant reduction (72$78 \%$ ) in cell survival (Figure 5B and 5C). In addition, the combination of PAK and PARP-targeting agents, did not merely produce cytostasis, but also resulted in cell death; increasing the frequency of apoptosis in PAK1 overexpressing and $P A K 1$-amplified breast cancer cells by nearly a factor of 3 (Figure 5D).

In order to demonstrate that these effects were dependent of PAK1 expression levels, HCC1419 cells were transfected with a vector encoding a myc-tagged wild type PAK1 (Figure S2A), and the effect of small molecule inhibitors of PAK and PARP on Rad51 foci formation was tested in cisplatin treated cells. Our results showed that the pharmacological inhibition of PAK alone or in combination with PARP in the myc-PAK1 overexpressing cells reduced their ability to form Rad51 foci in response to DNA damaging agents (Figure S2B), suggesting that the inhibition of this kinase in PAK1 overexpressing cells sensitize them to PARP pharmacological inhibition and has a negative impact in DNA repair by HR. In addition, survival and apoptosis of the myc-PAK1 overexpressing cells were tested as previously described. Interestingly, the colony formation ability of these cells was drastically reduced after PAK and PARP pharmacological inhibition, and also resulted in cell death (Figure S3).

\section{Pharmacological inhibition of PAK and PARP impairs tumor growth in vivo}

We next tested the effects of these small molecule inhibitors on the growth of SK-BR-3 xenografts. SKBR-3 cells were xenografted to severe combined immunodeficient (SCID) mice and tumors were allowed to 


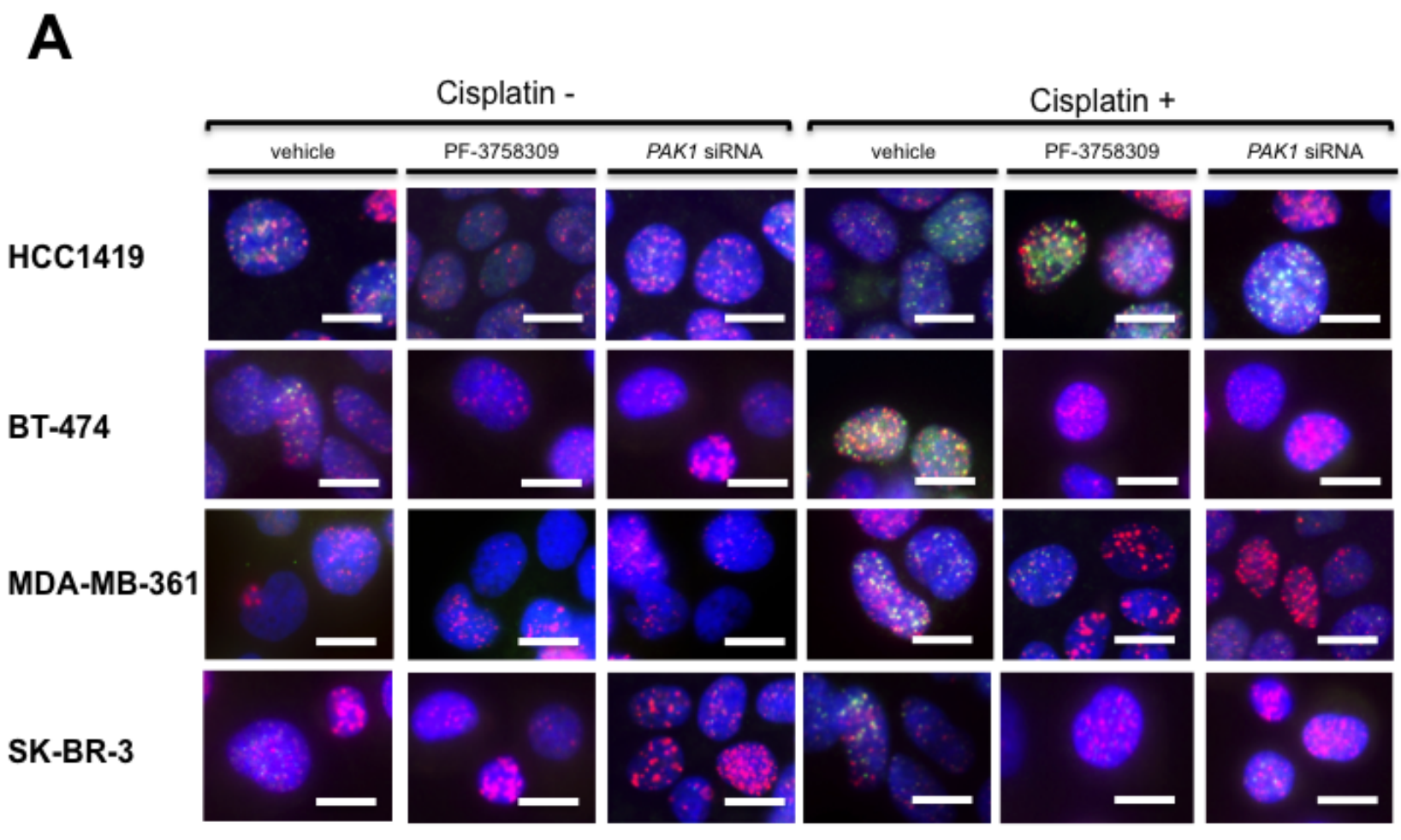

B

HCC1419

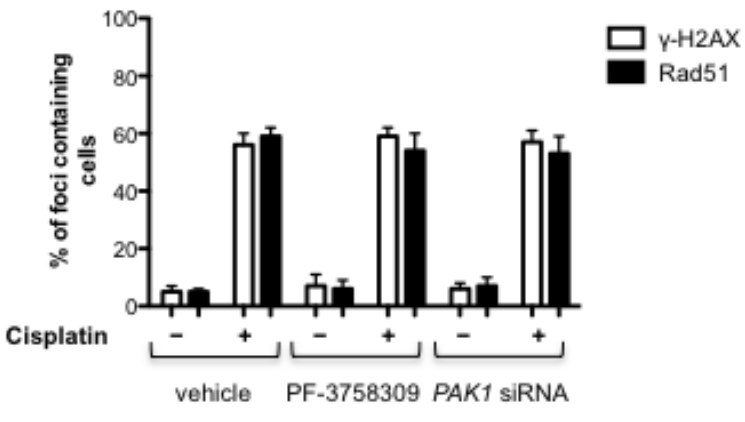

MDA-MB-361
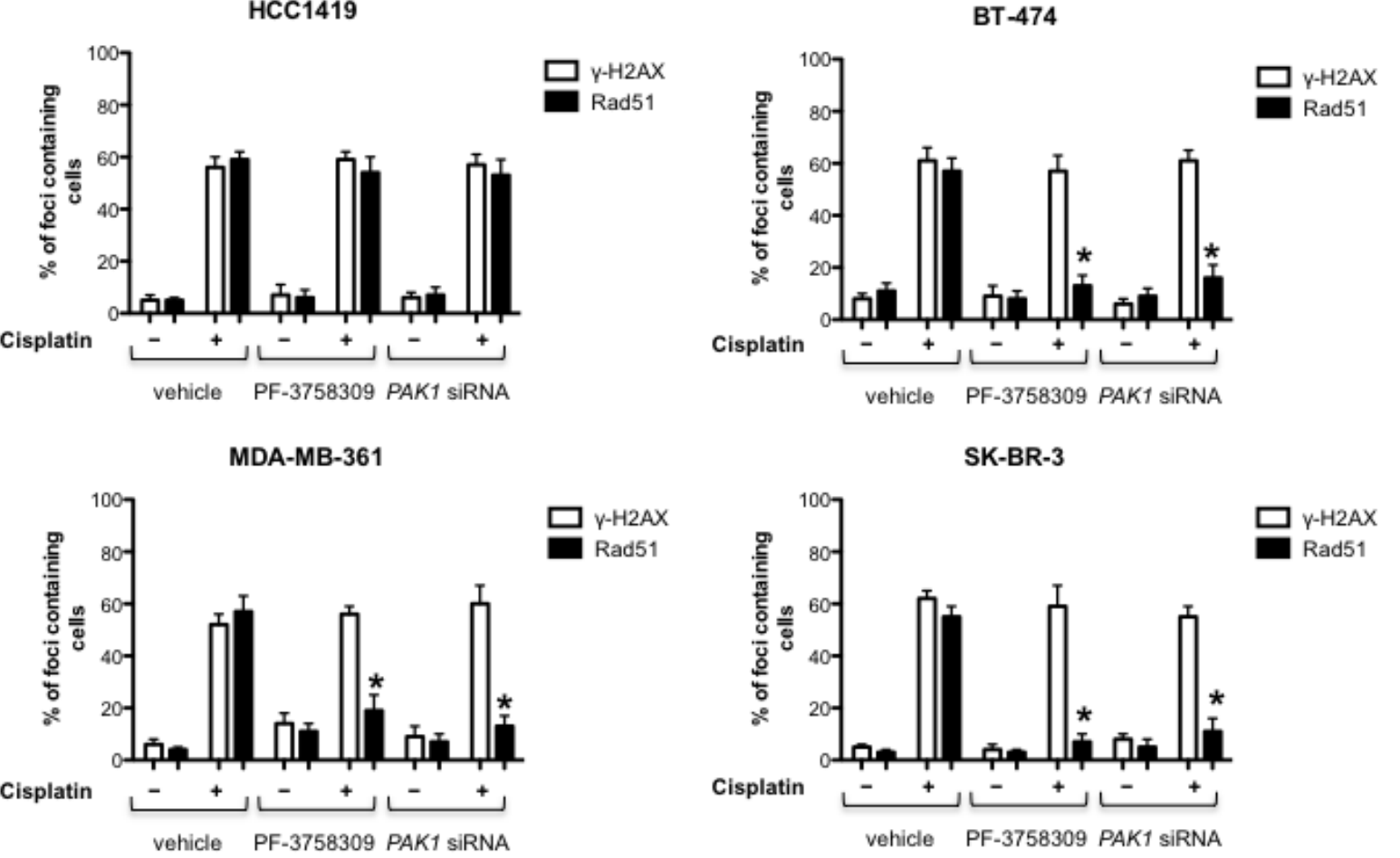

Figure 2: PAK inhibition reduces the formation of Rad51 foci. A. PAK inhibition affect DNA repair by homologous recombination in PAK1 overexpressing and/or PAK1-amplified breast cancer cells, but not in non-amplified brest cancer cells. HCC1419, BT-474, MDAMB-361 and SK-BR-3 cells were treated with vehicle, $1 \mu \mathrm{M}$ of the PAK inhibitor PF-3758309 or transfected with PAK1 targeting siRNAs, and incubated $24 \mathrm{~h}$ with or without $10 \mu \mathrm{M}$ cisplatin, fixed and stained with anti Rad51 (green), anti $\gamma$-H2AX (red) and DAPI (blue). The data are representative of 3 independent experiments. B. The graphics show the percent \pm SD of cells containing $\geq 5 \mathrm{Rad} 51$ and $\gamma-\mathrm{H} 2 \mathrm{AX}$ foci. The data are representative of 3 independent experiments. Bars $\pm \mathrm{SD}$. ${ }^{*} P>0.05,{ }^{*} P>0.001$. 
A

HCC1419

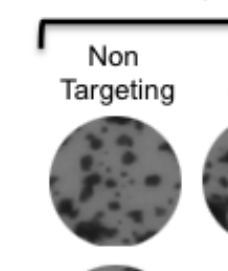

Cisplatin -

Cisplatin +

BT-474
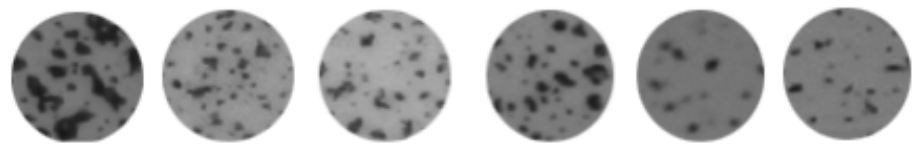

MDA-MB-361
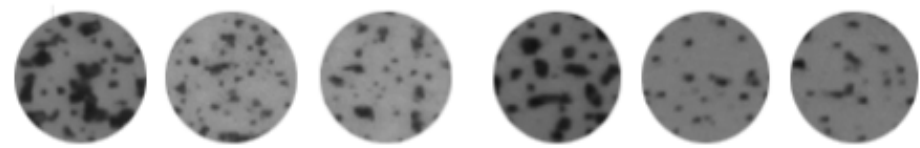

SK-BR-3
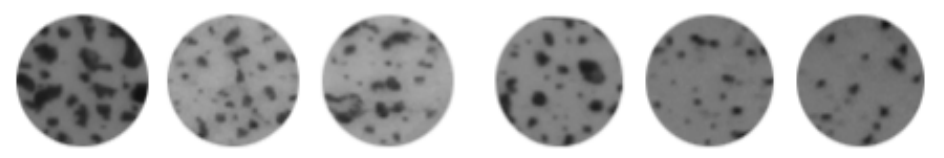

B

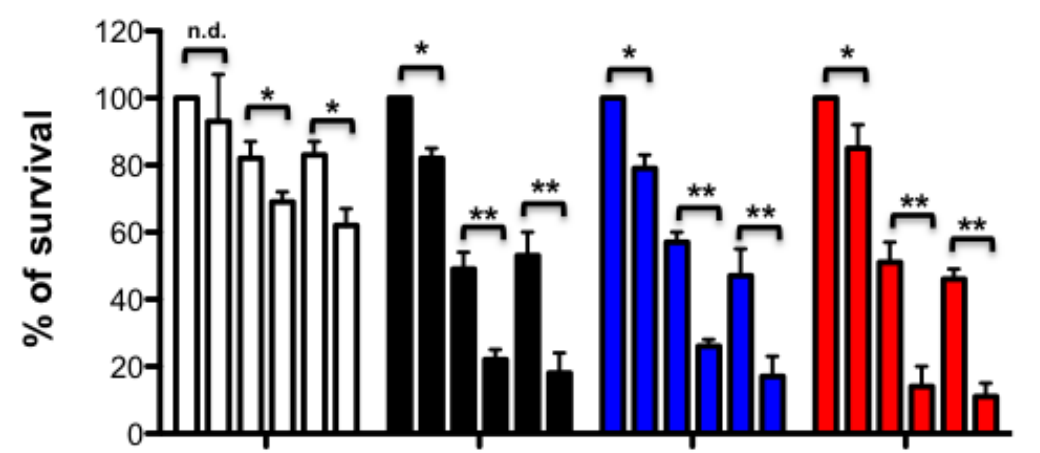

cisplatin PAK1 siRNA

PAK inhibitor

C

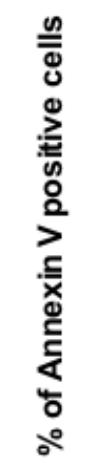
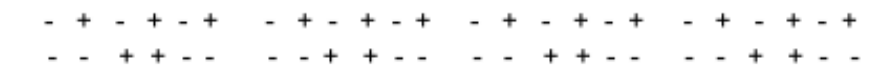

$\square \mathrm{HCC} 1419$

BT-474

MDA-MB-361

SK-BR-3

cisplatin

PAK1 siRNA

PAK inhibitor

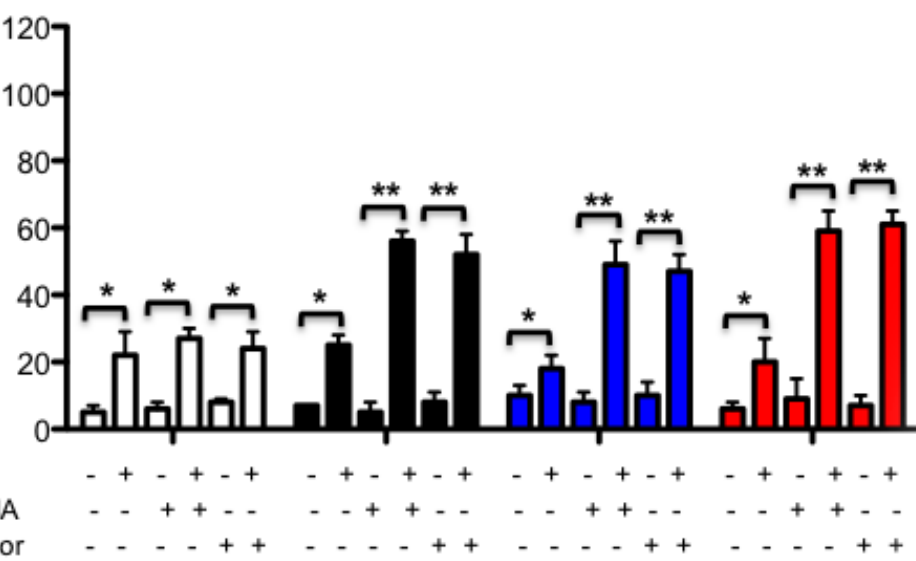

Figure 3: PAK inhibition reduces cell survival and promotes apoptosis. A. PAK inhibition sensitizes $P A K 1$ amplified breast cancer cells to cisplatin treatment. HCC1419, BT-474, MDA-MB-361 and SK-BR-3 cells were assessed for colony formation after vehicle or PF-3758309 treatment, or transfection with PAK1 targeting siRNAs in the presence or absence of cisplatin. Representative plates of three different experiments are shown. B. Mean survival is graphed after vehicle or PF-3758309 treatment, or transfection with PAKl targeting siRNAs plus or minus cisplatin, expressed as a percentage of colonies formed \pm SD compared to vehicle-treated cells. C. PAK inhibition and cisplatin treatment promotes apoptosis of PAK1-overexpressing and/or amplified breast cancer cells. Cells were treated as described in 3A for 4 days, collected, and apoptosis was measured calculating the percent of positive Annexin V-phycoerythrin cells by flow cytometry. The data are representative of 3 independent experiments. Bars $\pm \mathrm{SD} .{ }^{*} P>0.05,{ }^{*} P>0.001$. 
A
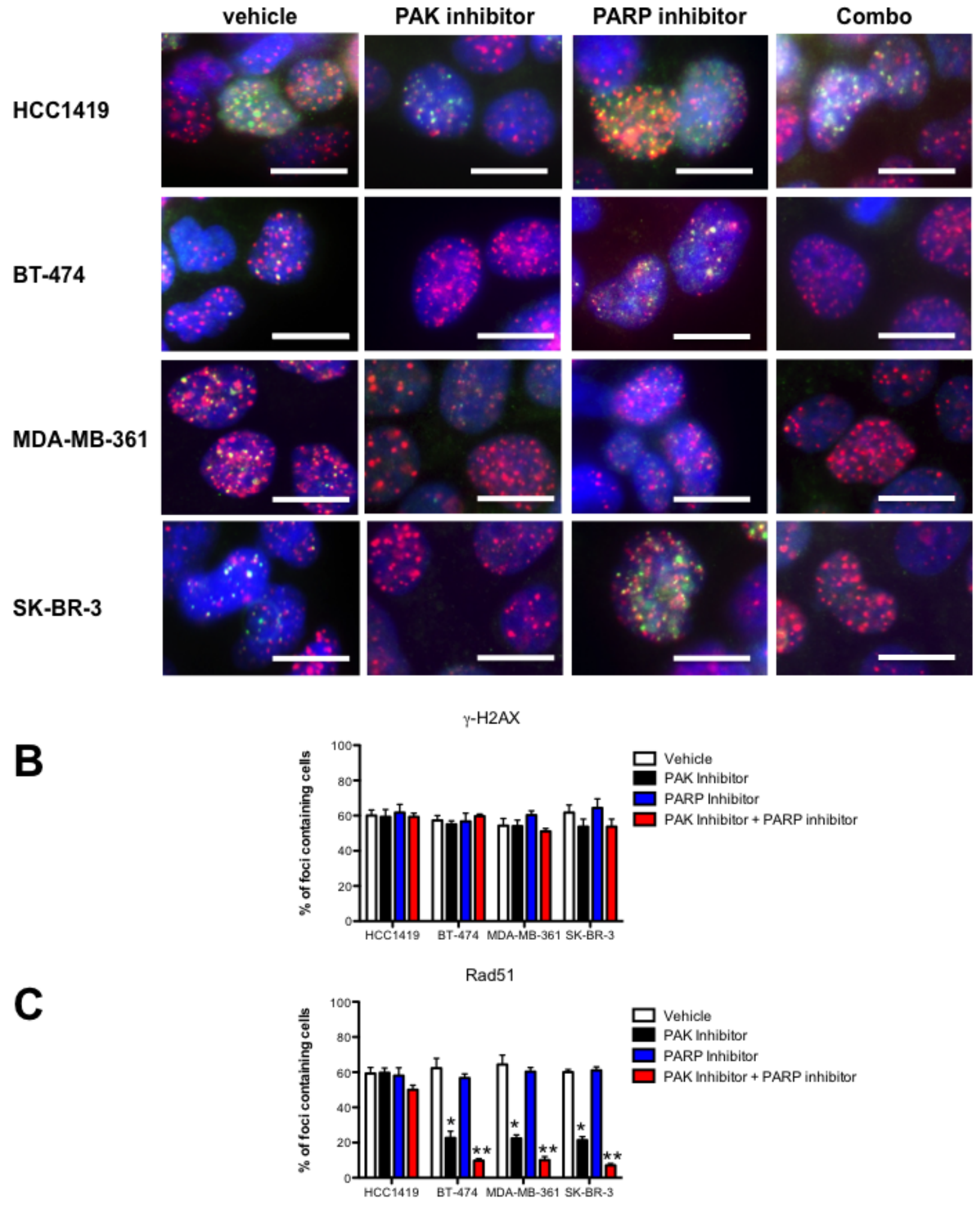

Figure 4: Combined PAK and PARP inhibition impairs DNA repair by Homologous Recombination in PAK overexpressing breast cancer cells. SK-BR-3, BT-474, MDA-MB-361 and HCC1419 cells were treated with vehicle, $1 \mu \mathrm{M}$ of the PAK inhibitor PF-3758309 and/or $1 \mu \mathrm{M}$ of rucaparib, and incubated $24 \mathrm{~h}$ with $10 \mu \mathrm{M}$ cisplatin, fixed and stained with anti Rad51 (green), anti $\gamma-\mathrm{H} 2 \mathrm{AX}$ (red) and DAPI (blue). B, The graphics show the percent \pm SD of cells containing $10 \operatorname{Rad} 51$ and $\gamma$-H2AX foci. The data are representative of 3 independent experiments. Bars $\pm \mathrm{SD} . * P>0.05, * * P>0.001$ 
A
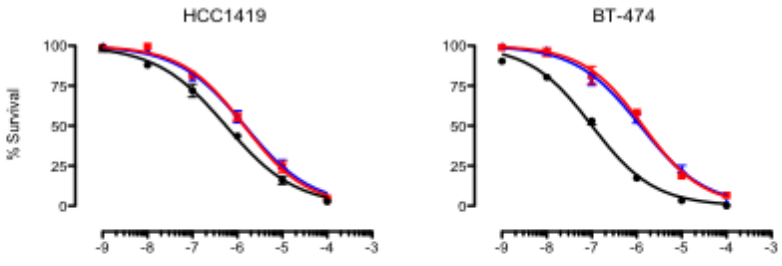

Drug Concentration [M]
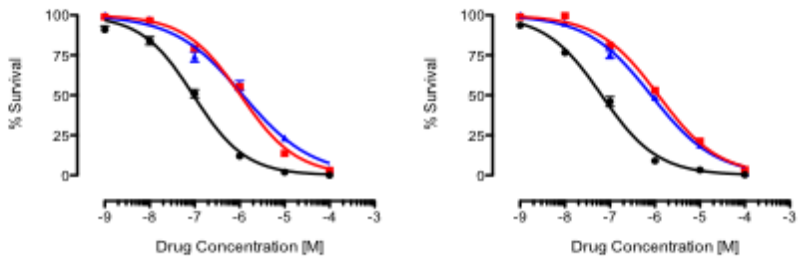

B

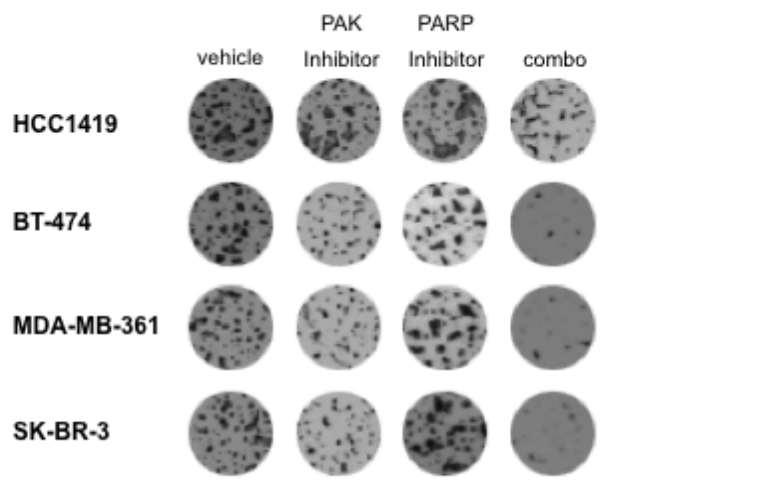

C

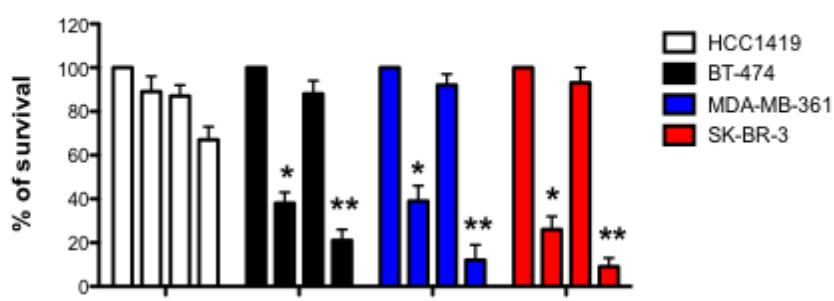

D
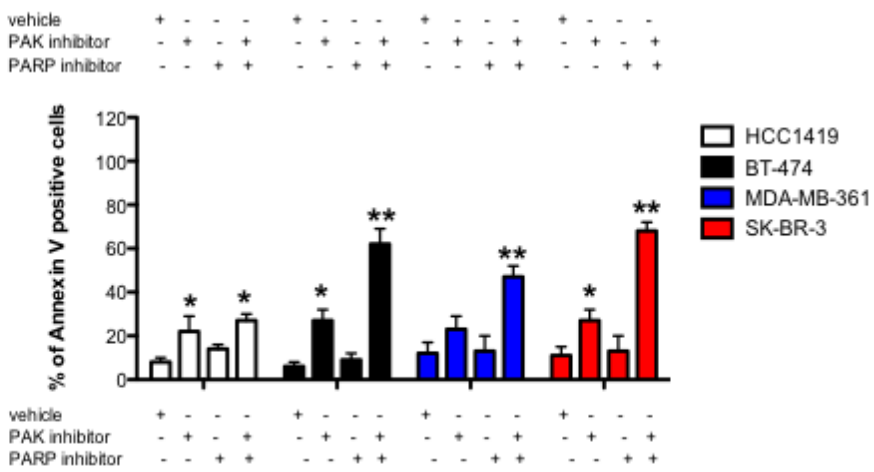

Figure 5: Combined PAK and PARP inhibition have a synergistic effect in vitro. A. Effect of PAK and PARP inhibitors on survival of PAK1-overexpressing breast cancer cells. HCC1419, BT-474, MDA-MB-361 and SK-BR-3 cells were treated with the indicated amounts of PF-3758309 (red lines), rucaparib (blue lines) or both drugs (black lines) for 4 days; cell viability was determined by Trypan blue exclusion. B. Combination of PF-3758309 and/or rucaparib treatment decreases cell survival of PAK1 overexpressing breast cancer cells. Cells were assessed for colony formation after vehicle, PF-3758309 and/or rucaparib treatment. Mean survival from three experiments is expressed as a percentage of colonies formed \pm SE relative to vehicle-treated cells. Representative plates are shown and mean survival is graphed after vehicle, PF-3758309 and/or rucaparib exposure, expressed as a percentage of colonies formed \pm SD compared to vehicle-treated cells. C. Combination of PF-3758309 and/or rucaparib treatment promotes apoptosis of PAK1 amplified and/or overexpressing breast cancer cells. Cells were treated with the indicated amounts of PF-3758309 and/or rucaparib for 4 days, collected, and apoptosis was measured calculating the percent of positive Annexin V-phycoerythrin cells by flow cytometry. The data are representative of 3 independent experiments. Bars $\pm \mathrm{SD} . * P>0.05, * * P>0.001$ 
form for 7 days. The mice were then treated with vehicle, PAK inhibitor PF-3758309, PARP inhibitor Rucaparib, or PF-3758309 plus Rucaparib, for 15 days. Tumor volumes were assessed every 3 days, and the animals were sacrificed at the end of the treatment.

Treatment with PF-3758309 had a marked negative effect on tumor growth, yielding tumors of about one-half the volume of tumors in untreated animals. Rucaparib alone did not affected tumor growth. Interestingly, animals treated with the combined PAK and PARP inhibitors showed no tumor growth (Figure 6A).

Analysis of markers of cell proliferation and apoptosis revealed that PF-3758309 treatment prevented cell proliferation and induced apoptosis, whereas
Rucaparib did not affect proliferation but slightly increased apoptosis. When coadministered, the inhibitors blocked proliferation and caused extensive apoptosis (Figure 6B).

\section{DISCUSSION}

The chromosomal region $11 \mathrm{q} 13$ is amplified in approximately $15-20 \%$ of breast cancers and has been associated with the presence of lymph node metastases, poor prognosis and lower survival rates [23-25]. A number of potential oncogenes have been mapped in this region, which have been suggested to play roles in the genesis and maintenance of breast cancer [26, 27].

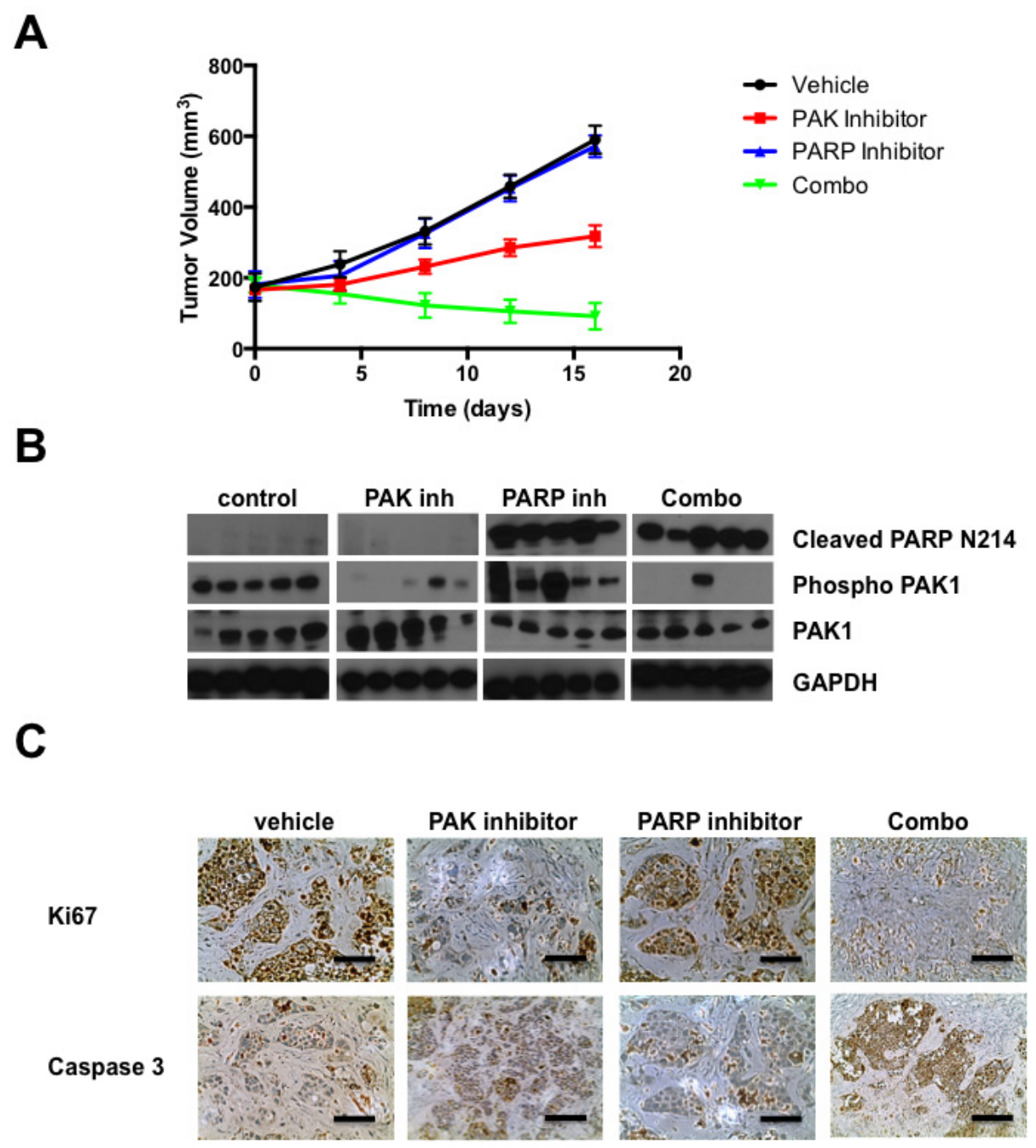

Figure 6: Pharmacological inhibition of PAK and PARP impairs tumor growth in vivo. Inhibition of PAK and PARP impedes the tumorigenicity of breast cancer cells. SK-BR-3 cells were injected into the mammary glands of C. B17/IcrSCID mice. Ten days after innoculation, the animals were treated with vehicle or PAK and/or PARP inhibitors for 15 days. A. Volumetric changes in tumor size between untreated mice (vehicle) and mice treated with inhibitors. B. Representative western blots showing PAK and PARP activity in tumors dissected from mice treated with vehicle or PAK and/or PARP inhibitors. C. Representative example of tumor sections between untreated mice and mice treated with PAK inhibitor, PARP inhibitor and a combination of PAK and PARP inhibitors stained for cleaved caspase-3 and Ki67. 
Table 1: Synergistic effect of PAK and PARP inhibitors.

CI (average \pm std. dev)

\begin{tabular}{|c|c|c|c|c|c|c|}
\hline Cell line & Inhibitors & & $\begin{array}{l}\text { Molar } \\
\text { ratio }\end{array}$ & ED50 & ED75 & ED95 \\
\hline HCC1419 & $\begin{array}{l}\text { PAK } \\
\text { inhibitor }\end{array}$ & $\begin{array}{l}\text { PARP } \\
\text { inhibitor }\end{array}$ & 1:1 & $\begin{array}{l}0.858 \pm \\
0.085\end{array}$ & $\begin{array}{l}0.963 \pm \\
0.126\end{array}$ & $\begin{array}{l}1.026 \pm \\
0.065\end{array}$ \\
\hline $\begin{array}{l}\text { MDA-MB- } \\
436\end{array}$ & $\begin{array}{l}\text { PAK } \\
\text { inhibitor }\end{array}$ & $\begin{array}{l}\text { PARP } \\
\text { inhibitor }\end{array}$ & 1:1 & $\frac{0.426 \pm}{\underline{0.103}}$ & $\begin{array}{l}\underline{0.483 \pm} \\
\underline{0.116}\end{array}$ & $\begin{array}{l}0.603 \pm \\
0.092\end{array}$ \\
\hline ВT-474 & $\begin{array}{l}\text { PAK } \\
\text { inhibitor }\end{array}$ & $\begin{array}{l}\text { PARP } \\
\text { inhibitor }\end{array}$ & 1:1 & $\frac{0.418 \pm}{\underline{0.078}}$ & $\begin{array}{l}\underline{0.502} \\
\pm 0.104\end{array}$ & $\frac{0.598 \pm 0 .}{\underline{133}}$ \\
\hline SK-BR-3 & $\begin{array}{l}\text { PAK } \\
\text { inhibitor }\end{array}$ & $\begin{array}{l}\text { PARP } \\
\text { inhibitor }\end{array}$ & $1: 1$ & $\frac{0.402 \pm}{\underline{0.036}}$ & $\frac{0.496 \pm}{\underline{0.122}}$ & $\frac{0.516 \pm}{\underline{0.042}}$ \\
\hline
\end{tabular}

Summary results of drug interactions calculated as Chou-Talalay CI based on CellTiter-Blue viability determinations. CI values $<0.5$ (underlined) indicated strong synergy between the two small molecule inhibitors in producing cytotoxic effect.

The PAK1 gene, which resides in 11q13.5, has previously been implicated in breast cancers and other cancers that contain this amplicon. It has been shown that PAK1 gene is frequently amplified in human breast cancer; PAK1 amplification is associated with resistance to tamoxifen; transgenic expression of an activated PAK1 allele induces transformation of mammary epithelial cells in culture and induces breast cancer in mice; and expression of dominant-negative alleles, shRNAs, or treatment with PAK inhibitors, impede the growth and/ or normalize the morphology of various breast cancer cell lines in tissue culture [28-32]. However, none of these studies examined the effect of PAK1 inhibition in the genetic profile of breast cancer cells, nor did they use clinically relevant small molecule inhibitors. In this study, we show that (a) blockade of PAK1 expression or activity in vitro down-regulates the expression of $\mathrm{FA} / \mathrm{BRCA}$ pathway genes, (b) knock down or pharmacological inhibition of PAK in PAK1 overexpressing cells, compromises the ability of these cells to form $\operatorname{Rad} 51$ foci, (c) loss of PAK function reduces cell survival and promotes apoptosis, (d) PAK inhibition in PAK1 overexpressing breast cancer cells, sensitize these cells to PARP inhibition, and (e) small molecule inhibitors of PAK and PARP have a synergistic effect in vitro, and impair tumor growth in a xenograft setting.

The molecular mechanism by which PAK influences the expression of FA/BRCA genes is unknown. However, recent studies have demonstrated that all the genes of the FA/BRCA family posses a highly conserved promoter region [33], which contains DNA binding sites for transcription factors that are phosphorylated and activated by PAK1. This is the case of NF- $\kappa B$, which is activated by PAK1, allowing the translocation of the $\mathrm{p} 65$ subunit into the nucleus where it acts as a transcription factor [34]. Another studies have also shown that even when
PAK1 cannot bind directly to the DNA, it can form part of transcriptionally active complexes $[5,13,35]$, suggesting that PAK1 could promote the transcription of FA/BRCA genes directly or indirectly. In addition, a recent study has shown that $P A K 1$ overexpression correlates with the expression of $F A / B R C A$ genes in inflammatory breast cancer samples [17]. Finally, our results of a TCGA analysis showed that PAKl overexpression in human breast cancer specimens correlates with the expression of most $F A / B R C A$ genes.

Interestingly, we observed that depletion or pharmacological inhibition of PAK in PAK1 overexpressing breast cancer cells, drastically reduced the expression of FANCI and FANCD2, cell survival and the ability of these cells to form Rad51 foci in response to DNA damaging agents, but in contrast, PAK inhibition only had a modest effect in these cellular processes in breast cancer cells that express low levels of PAK1. These findings are consistent with a previous report showing a strong correlation between PAK1 expression and the expression of proteins involved in DNA damage response in Primary Esophageal Small Cell Carcinoma (PESCC) [36], suggesting that PAK1 may be an important player in this cellular process.

Remarkably, we found that PAK inhibition sensitizes PAK1 overexpressing breast cancer cells to PARP inhibition. It is well documented that FA/BRCA-defective cells and other cells defective in HR are highly susceptible to PARP small molecule inhibitors [11]. Therefore, the down-regulation of FA/BRCA genes mediated by PAK1 creates a state of "FA/BRCAness", and represents a rational approach for expanding the efficacy of PARP inhibitors to FA/BRCA-proficient cancer populations. 


\section{MATERIALS AND METHODS}

\section{Cell culture, expression plasmids and transfection}

The mouse tumor derived breast cancer cell lines Neu:PAK $1^{+/+}$and Neu:PAK $1^{-/}$were maintained in low calcium medium supplemented with $5 \%$ horse serum, $50 \mathrm{U} / \mathrm{mL}$ penicillin, and $50 \mathrm{mg} / \mathrm{mL}$ streptomycin as previously described [14]. Wild type 10A.ErbB2 cells (MCF-10A cells expressing a chimeric form of ErbB2) and 10A.ErbB2 cells expressing a tetracycline inducible shRNA against PAK1 (described in [14]) were maintained in DMEM/F12 (Gibco BRL) supplemented with 5\% donor horse serum, $20 \mathrm{ng} / \mathrm{mL}$ EGF (Harlan Bioproducts), $10 \mathrm{mg}$ / $\mathrm{mL}$ insulin (Sigma), $1 \mathrm{ng} / \mathrm{mL}$ cholera toxin (Sigma), 100 $\mathrm{mg} / \mathrm{mL}$ hydrocortisone (Sigma), $50 \mathrm{U} / \mathrm{mL}$ penicillin, and $50 \mathrm{mg} / \mathrm{mL}$ streptomycin [37]. HCC1419, MDA-MB-361, BT-474, and SK-BR3 were obtained from American Type Culture Collection, HCC1419 and MDA-MB-361cells were grown in RPMI-1640 supplemented with 10\% FBS, BT-474 cells were grown in DMEM/F12 supplemented with 10\% FBS and SK-BR3 were grown in McCoy's 5A supplemented with $10 \%$ FBS.

For transient transfection experiments, the pCMV6M-PAK1 vector was transfected into HCC1419 cells by using Lipofectamine 2000 (Invitrogene).

\section{Microarrays}

RNA from the mouse tumor derived breast cancer cell lines Neu:PAK $1^{+/+}$and Neu:PAK $1^{-/}$, and from the human MCF10A.B2 and MCF10A.B2 cells expressing a shRNA against PAK1, was purified from wholecell lysates using the RNeasy mini kit (Qiagen), and contaminating DNA was removed using a RNase-free DNase set. A quantity amounting to $500 \mathrm{ng}$ total RNA was amplified and labeled using the low RNA input linear amplification kit (Agilent). Labeled cRNA targets were hybridized onto human or mouse whole genome arrays. Microarray images were processed using Agilent Feature Extraction software (version 9.5). Data were background corrected using the normexp method (PMID: 17720982) implemented in the Bioconductor package limma, and quantile normalized. Identification of differentially expressed genes was performed with empirical Bayes moderated $t$ tests using limma. Biological pathways and networks were examined with Ingenuity Pathway Analysis software (www.ingenuity.com). The microarray original data have been submitted to Gene Expression Omnibus (GEO) database (Accession number: GSE72206).

\section{Real-time PCR}

Total RNA was extracted from cells using RNeasy Mini kits, quantified by Nanodrop ND-1000 and reverse transcribed using the High Capacity cDNA Reverse Transcription Kit (Applied Biosystems). 1 ng cDNA was amplified by real time PCR using Universal ProbeLibrary (UPL) probes (Roche). The sequences for the primers for real-time qPCR were: FANCI Fwd: 5' cagctgtgtggacaccttgt 3', Rev: 5' aattcctccggagctctgac 3'; FANCD2 Fwd; 5': cccagaactgatcaactctcct 3', Rev: 5' ccatcatcacacggaagaaa 3'; PAK1 Fwd: 5' tgtggagaagagaggttcagc 3', Rev: 5' gctgcagcaatcagtgga 3'; and GAPDH Fwd: 5' ccccggtttctataaattgagc 3', Rev: 5' caccttccccatggtgtct 3'. UPL probes used were \#80 for FANCI, \#69 for FANCD2, \#19 for PAK1 and \#63 for GAPDH. Each sample was run in $20 \mu \mathrm{l}$ reaction using $2 \mathrm{X}$ FastStart Universal Probe Master with ROX (Roche). Reactions were performed in an ABI real time PCR 7500 (Applied Biosystems, Foster City, CA). Ratios of mRNA levels to control values were calculated using the $\Delta \mathrm{Ct}$ method $\left(2^{-\Delta \Delta \mathrm{Ct}}\right)$ at a threshold of 0.02 [38]. All data were normalized to control GAPDH. PCR conditions used: hold for $10 \mathrm{~min}$ at $95^{\circ} \mathrm{C}$, followed by 40 cycles of $15 \mathrm{~s}$ at $95^{\circ} \mathrm{C}$ and $60 \mathrm{~s}$ at $60^{\circ} \mathrm{C}$.

\section{Immunofluorescence and confocal microscopy}

PAK1 amplified, overexpressing and non-amplified breast cancer cells were grown on cover slips in the presence of cisplatin and/or the PAK inhibitor PF-3758309 and/or the PARP inhibitor rucaparib. Cells were then fixed with $4 \%$ paraformaldehyde for $30 \mathrm{~min}$, washed three times with PBS, permeabilized with $0.5 \%$ Triton X-100 for $10 \mathrm{~min}$ and blocked with $1 \%$ albumin in PBS for 30 min at room temperature. Cells were incubated overnight with antibodies specific for $\gamma$-H2AX (pSer139) (Upstate Biotechnology 05-636, clone JBW301), and Rad51 (Santa Cruz Biotechnology sc8349, clone H-92), washed three times with PBS and incubated with Alexa Fluor 488 conjugated secondary antibodies (Life Technologies). The nucleus were counterstained with DAPI (4',6'-diamidino2-phenylindole). Confocal analyses were performed with a Nikon TE2000 confocal microscopy system and the number of foci per cell was calculated by dividing the total number of foci in the frame to the number of cells containing foci.

\section{Colony formation assays}

For colony formation assays, SK-BR3 (PAK1 amplified), BT-474 and MDA-MB-361 (PAK overexpressing) and $\mathrm{HCC} 1419$ (non-amplified) cells were seeded in six-well plates at 1,000 cells per well in the presence of cisplatin and/or the PAK inhibitor PF-3758309 
and/or the PARP inhibitor rucaparib. Colony formation was assessed 2 weeks after plating with crystal violet staining. For siRNA treatments, exponentially growing cells were reverse-transfected with Dharmacon siRNAs targeting PAK1 in 24-well plates, and $2 \mathrm{~d}$ post-transfection cells were treated with cisplatin or rucaparib and then replated in six-well plates for colony formation. Mean colony formation from three experiments was expressed as percentage of colonies $\pm \mathrm{SE}$ relative to vehicle-treated cells.

\section{Apoptosis analyses}

Apoptosis was measured using the Annexin V-PE Apoptosis Detection kit (BD Pharmingen) followed by flow cytometry. Amplified, overexpressing and nonamplified PAK1 breast cancer cells $\left(2 \times 10^{5}\right)$ were seeded in six-well cell culture plates and treated with vehicle, cisplatin and/or the PAK inhibitor PF-3758309. Both floating and attached cells were collected $4 \mathrm{~d}$ after cell seeding, washed twice with cold PBS, and suspended in $1 \times$ binding buffer. A $100 \mu \mathrm{L}$ aliquot of the cell suspension (representing $5 \times 10^{4}$ cells) was transferred to a culture tube, to which $5 \mu \mathrm{L}$ of Annexin V-PE and $5 \mu \mathrm{L}$ of 7 aminoactinomycin D (7-AAD) were added, and the mix was incubated for $15 \mathrm{~min}$ at room temperature in the dark. Apoptosis analysis was carried out using a FACScan and FlowJo software version 7.2. A total of 10,000 cells were collected for each sample for analysis.

\section{Drug synergy testing}

The combination index (CI) between pharmacological inhibitors was established by the ChouTalalay method [39]. We used the software package CalcuSyn (BioSoft, UK) to automate calculations. Briefly, for each drug tested, an IC50 curve was established in each cell line, and used to select combination doses of drugs for subsequent synergy tests. 3500 cells were plated per well in 96-well plates. After 24 hours, cells were treated with serial dilutions of individual inhibitors or combinations of two inhibitors maintained at a constant molar ratio. After 72 hours incubation, cell viability was measured using either CellTiter Blue (Promega, USA) or a WST1 assay (Roche Applied Science, Indianapolis, IN). The CI values for each dose and corresponding cytotoxicity were expressed as the fraction affected $(\mathrm{Fa})$ and were calculated using CalcuSyn computer software and presented as Fa-CI plots.

\section{Tissue preparation, histology, immuno- histochemistry, and immunoblotting}

All tumor samples and control tissues were fixed overnight in $4 \%$ paraformaldehyde, dehydrated, and embedded in paraffin. Hematoxylin and eosin (H\&E)stained sections were used for diagnostic purposes and unstained sections for immunohistochemical studies. Protein concentration was determined, and equal amounts of total proteins were separated on SDS- PAGE. IHC was performed with the following antibodies: rabbit polyclonal antibody for Cleaved Caspase-3 (Cell Signaling) and Ki-67 (Santa Cruz Biotechnology). The evaluation of the IHC was conducted blindly, without knowledge of the treatment. Immunoblot analyses were performed on lysates extracted from tumors. Antibodies used for western blot included PAK1, phospho-PAK1, cleaved caspase-3, H2AX and phospho-H2AX from Cell Signaling Technology; Rad51, FANCI, FANCD2 and Ki-67 were from Santa Cruz Biotechnology. GAPDH was used as loading control.

\section{Tumor xenografts}

Four- to 6-week-old inbred C.B17/Icr-SCID mice were obtained from the Jackson Labs. SK-BR-3 cells (5 $\mathrm{x} 10^{6}$ in $0.3 \mathrm{ml}$ of $\mathrm{rBM}$ ) were injected into the mammary fat pad of each mouse. Mice were treated with either vehicle or PAK inhibitor PF-3758309 at dose of $20 \mathrm{mg} /$ $\mathrm{kg} /$ day, PARP inhibitor at dose of $50 \mathrm{mg} / \mathrm{kg} / \mathrm{day}$, in the combination groups, the compounds were given with 4-6 h interval. At completion of all xenograft studies mice were sacrificed, the tumors were excised and tumor volumes estimated with the following formula: volume $=$ ( $\mathrm{a} 2 \mathrm{X} \mathrm{b}$ ) / 2, where $\mathrm{a}=$ short and $\mathrm{b}=$ long tumor lengths, respectively, in millimeters.

\section{Statistical analysis}

Statistical analysis was conducted using the unpaired Student $\mathrm{t}$ test except for survival curves where the $\log P$ rank test was used. Values of $P<0.05$ were considered significant

\section{ACKNOWLEDGMENTS}

We thank Laboratorio de Especialidades Inmunológicas S.A. de C.V. for the donation of a tissue culture hood and the cell lines BT474 and SK-BR-3, and Dr. Genaro Patiño-Lopez for his technical support. This work was supported by grants from the UNAM (PAPIIT IA204115) to LEAR, from the NIH (R01 CA148805 and R01 CA098830) to JC, and NIH CORE Grant CA06927, and an appropriation from the state of Pennsylvania to the 
Fox Chase Cancer Center.

\section{CONFLICTS OF INTEREST}

No potential conflict of interest are disclosed.

\section{Editorial note}

This paper has been accepted based in part on peerreview conducted by another journal and the authors' response and revisions as well as expedited peer-review in Oncotarget.

\section{REFERENCES}

1. Bokoch GM. Biology of the p21-activated kinases. Annu Rev Biochem. 2003; 72:743-781.

2. Arias-Romero LE and Chernoff J. A tale of two Paks. Biol Cell. 2008; 100:97-108.

3. Radu M, Semenova G, Kosoff R and Chernoff J. PAK signalling during the development and progression of cancer. Nat Rev Cancer. 2014; 14:13-25.

4. Malecka KA, Szentpetery Z and Peterson JR. Synergistic activation of $\mathrm{p} 21$-activated kinase 1 by phosphatidylinositol 4,5-bisphosphate and Rho GTPases. The Journal of biological chemistry. 2013; 288:8887-8897.

5. Singh RR, Song C, Yang Z and Kumar R. Nuclear localization and chromatin targets of $\mathrm{p} 21$-activated kinase 1. J Biol Chem. 2005; 280:18130-18137.

6. Barros P, Jordan P and Matos P. Rac1 signaling modulates BCL-6-mediated repression of gene transcription. Mol Cell Biol. 2009; 29:4156-4166.

7. Li DQ, Nair SS, Ohshiro K, Kumar A, Nair VS, Pakala SB, Reddy SD, Gajula RP, Eswaran J, Aravind L and Kumar R. MORC2 signaling integrates phosphorylation-dependent, ATPase-coupled chromatin remodeling during the DNA damage response. Cell Rep. 2012; 2:1657-1669.

8. Motwani M, Li DQ, Horvath A and Kumar R. Identification of novel gene targets and functions of p21-activated kinase 1 during DNA damage by gene expression profiling. PLoS One. 2013; 8:e66585.

9. Ashworth A. A synthetic lethal therapeutic approach: poly(ADP) ribose polymerase inhibitors for the treatment of cancers deficient in DNA double-strand break repair. J Clin Oncol. 2008; 26:3785-3790.

10. Bryant HE, Schultz N, Thomas HD, Parker KM, Flower D, Lopez E, Kyle S, Meuth M, Curtin NJ and Helleday T. Specific killing of BRCA2-deficient tumours with inhibitors of poly(ADP-ribose) polymerase. Nature. 2005; 434:913917.

11. Farmer H, McCabe N, Lord CJ, Tutt AN, Johnson DA, Richardson TB, Santarosa M, Dillon KJ, Hickson I, Knights C, Martin NM, Jackson SP, Smith GC and Ashworth A.
Targeting the DNA repair defect in BRCA mutant cells as a therapeutic strategy. Nature. 2005; 434:917-921.

12. $\mathrm{Li} \mathrm{M}$ and $\mathrm{Yu} \mathrm{X}$. The role of poly(ADP-ribosyl)ation in DNA damage response and cancer chemotherapy. Oncogene. 2014.

13. Arun B, Akar U, Gutierrez-Barrera AM, Hortobagyi GN and Ozpolat B. The PARP inhibitor AZD2281 (Olaparib) induces autophagy/mitophagy in BRCA1 and BRCA2 mutant breast cancer cells. Int J Oncol. 2015.

14. Arias-Romero LE, Villamar-Cruz O, Huang M, Hoeflich $\mathrm{KP}$ and Chernoff J. Pak1 kinase links ErbB2 to beta-catenin in transformation of breast epithelial cells. Cancer Res. $2013 ; 73: 3671-3682$

15. Monk BJ, Ghatage P, Parekh T, Henitz E, Knoblauch R, Matos-Pita AS, Nieto A, Park YC, Cheng PS, Li W, Favis R, Ricci D and Poveda A. Effect of BRCA1 and XPG mutations on treatment response to trabectedin and pegylated liposomal doxorubicin in patients with advanced ovarian cancer: exploratory analysis of the phase 3 OVA301 studydagger. Ann Oncol. 2015; 26:914-920.

16. Sikov WM. Assessing the role of platinum agents in aggressive breast cancers. Curr Oncol Rep. 2015; 17:3.

17. Yellapu NK, Pulaganti M and Babu PS. Bioinformatics Exploration of PAK1 (P21-activated kinase-1) Revealed Potential Network Gene Elements in Breast Invasive Carcinoma. J Biomol Struct Dyn. 2016:1-27.

18. Bhattacharyya A, Ear US, Koller BH, Weichselbaum RR and Bishop DK. The breast cancer susceptibility gene BRCA1 is required for subnuclear assembly of Rad51 and survival following treatment with the DNA cross-linking agent cisplatin. J Biol Chem. 2000; 275:23899-23903.

19. Murray BW, Guo C, Piraino J, Westwick JK, Zhang C, Lamerdin J, Dagostino E, Knighton D, Loi CM, Zager M, Kraynov E, Popoff I, Christensen JG, Martinez R, Kephart SE, Marakovits J, et al. Small-molecule p21activated kinase inhibitor PF-3758309 is a potent inhibitor of oncogenic signaling and tumor growth. Proc Natl Acad Sci U S A. 2010; 107:9446-9451.

20. Fong PC, Boss DS, Yap TA, Tutt A, Wu P, MerguiRoelvink M, Mortimer P, Swaisland H, Lau A, O'Connor MJ, Ashworth A, Carmichael J, Kaye SB, Schellens JH and de Bono JS. Inhibition of poly(ADP-ribose) polymerase in tumors from BRCA mutation carriers. N Engl J Med. 2009; 361:123-134.

21. Tutt AN, Lord CJ, McCabe N, Farmer H, Turner N, Martin NM, Jackson SP, Smith GC and Ashworth A. Exploiting the DNA repair defect in BRCA mutant cells in the design of new therapeutic strategies for cancer. Cold Spring Harb Symp Quant Biol. 2005; 70:139-148.

22. Plummer R, Lorigan P, Steven N, Scott L, Middleton MR, Wilson RH, Mulligan E, Curtin N, Wang D, Dewji R, Abbattista A, Gallo J and Calvert H. A phase II study of the potent PARP inhibitor, Rucaparib (PF-01367338, AG014699), with temozolomide in patients with metastatic 
melanoma demonstrating evidence of chemopotentiation. Cancer Chemother Pharmacol. 2013; 71:1191-1199.

23. Schuuring E, Verhoeven E, van Tinteren H, Peterse JL, Nunnink B, Thunnissen FB, Devilee P, Cornelisse CJ, van de Vijver MJ, Mooi WJ and et al. Amplification of genes within the chromosome $11 \mathrm{q} 13$ region is indicative of poor prognosis in patients with operable breast cancer. Cancer research. 1992; 52:5229-5234.

24. van de Vijver MJ, He YD, van't Veer LJ, Dai H, Hart AA, Voskuil DW, Schreiber GJ, Peterse JL, Roberts C, Marton MJ, Parrish M, Atsma D, Witteveen A, Glas A, Delahaye $\mathrm{L}$, van der Velde $\mathrm{T}$, et al. A gene-expression signature as a predictor of survival in breast cancer. The New England journal of medicine. 2002; 347:1999-2009.

25. Adnane J, Gaudray P, Simon MP, Simony-Lafontaine J, Jeanteur $\mathrm{P}$ and Theillet $\mathrm{C}$. Proto-oncogene amplification and human breast tumor phenotype. Oncogene. 1989; 4:13891395.

26. Lundgren K, Holm K, Nordenskjold B, Borg A and Landberg G. Gene products of chromosome 11q and their association with CCND1 gene amplification and tamoxifen resistance in premenopausal breast cancer. Breast Cancer Res. 2008; 10:R81.

27. Wilkerson PM and Reis-Filho JS. The 11q13-q14 amplicon: clinicopathological correlations and potential drivers. Genes Chromosomes Cancer. 2013; 52:333-355.

28. Li Q, Mullins SR, Sloane BF and Mattingly RR. p21Activated kinase 1 coordinates aberrant cell survival and pericellular proteolysis in a three-dimensional culture model for premalignant progression of human breast cancer. Neoplasia. 2008; 10:314-329.

29. Arias-Romero LE, Villamar-Cruz O, Pacheco A, Kosoff R, Huang M, Muthuswamy SK and Chernoff J. A RacPak signaling pathway is essential for ErbB2-mediated transformation of human breast epithelial cancer cells. Oncogene. 2010; 29:5839-5849.

30. Balasenthil S, Sahin AA, Barnes CJ, Wang RA, Pestell RG, Vadlamudi RK and Kumar R. p21-activated kinase-1 signaling mediates cyclin D1 expression in mammary epithelial and cancer cells. J Biol Chem. 2004; 279:14221428.
31. Ong CC, Jubb AM, Haverty PM, Zhou W, Tran V, Truong T, Turley H, O’Brien T, Vucic D, Harris AL, Belvin M, Friedman LS, Blackwood EM, Koeppen H and Hoeflich KP. Targeting p21-activated kinase 1 (PAK1) to induce apoptosis of tumor cells. Proc Natl Acad Sci U S A. 2011; 108:7177-7182.

32. Shrestha Y, Schafer EJ, Boehm JS, Thomas SR, He F, Du J, Wang S, Barretina J, Weir BA, Zhao JJ, Polyak K, Golub TR, Beroukhim R and Hahn WC. PAK1 is a breast cancer oncogene that coordinately activates MAPK and MET signaling. Oncogene. 2012; 31:3397-3408.

33. Meier D and Schindler D. Fanconi anemia core complex gene promoters harbor conserved transcription regulatory elements. PLoS One. 2011; 6:e22911.

34. Friedland JC, Lakins JN, Kazanietz MG, Chernoff J, Boettiger D and Weaver VM. alpha6beta4 integrin activates Rac-dependent p21-activated kinase 1 to drive NF-kappaBdependent resistance to apoptosis in 3D mammary acini. J Cell Sci. 2007; 120:3700-3712.

35. Jagadeeshan S, Krishnamoorthy YR, Singhal M, Subramanian A, Mavuluri J, Lakshmi A, Roshini A, Baskar G, Ravi M, Joseph LD, Sadasivan K, Krishnan A, Nair AS, Venkatraman G and Rayala SK. Transcriptional regulation of fibronectin by p21-activated kinase-1 modulates pancreatic tumorigenesis. Oncogene. 2015; 34:455-464.

36. Gan J, Zhang Y, Ke X, Tan C, Ren H, Dong H, Jiang J, Chen S, Zhuang Y and Zhang H. Dysregulation of PAK1 Is Associated with DNA Damage and Is of Prognostic Importance in Primary Esophageal Small Cell Carcinoma. Int J Mol Sci. 2015; 16:12035-12050.

37. Muthuswamy SK, Li D, Lelievre S, Bissell MJ and Brugge JS. ErbB2, but not ErbB1, reinitiates proliferation and induces luminal repopulation in epithelial acini. Nat Cell Biol. 2001; 3:785-792.

38. Livak KJ and Schmittgen TD. Analysis of relative gene expression data using real-time quantitative PCR and the 2(-Delta Delta C(T)) Method. Methods. 2001; 25:402-408.

39. Chou TC and Talalay P. Quantitative analysis of dose-effect relationships: the combined effects of multiple drugs or enzyme inhibitors. Adv Enzyme Regul. 1984; 22:27-55. 